\title{
SWOT Analysis Based on Heilongjiang University Curriculum Ideological and Political Research
}

\author{
Caiyu Liu ${ }^{1, *}$ and $\mathrm{Han} \mathrm{Ni}^{1}$ \\ ${ }^{1}$ Centre for research in higher education, Northeast Petroleum University, Daqing, Heilongjiang 163000, China \\ * Corresponding author. Email: 1692616244@qq.com
}

\begin{abstract}
Colleges and universities in Heilongjiang province undertake cultivating talents, which is a crucial part of curriculum ideological and political work. This paper uses the SWOT analysis method to analyze the internal advantages and disadvantages as well as external opportunities and challenges of ideological and political politics in colleges and universities in Heilongiiang Province, and puts forward corresponding suggestions. Therefore, Heilongjiang province should actively promote curriculum ideological and political work, improve their awareness of participation, learn from the relevant experience, and work to increase income and reduce expenditure.
\end{abstract}

Keywords: curriculum ideology and politics, Colleges and universities, Heilongjiang Province, SWOT

Analysis

\section{INTRODUCTION}

In 2014, the concept of curriculum ideology and politics was first proposed in China, and a group of pilot schools were selected to promote it. In 2020, the Ministry of Education issued the Guiding Outline for the Construction of Ideological and Political Courses in Colleges and Universities, pushing the construction of ideological and political courses to a climax. In response to the national call, Heilongjiang province fully implemented the ideological and political construction of curriculum, issued corresponding work plans, launched the first batch of 186 demonstration projects in the province, mined and developed "red, green, blue, gold and silver" educational resources, highlighted the characteristics of Longjiang, organized training for more than 8,000 front-line teachers in the province, and gave play to the spirit of example. To build the country's first province-wide ideological and political education alliance for graduate courses, and compiled the design of six ideological and political textbooks for physics courses. Heilongjiang province curriculum ideological and political achievements, but there is still a lot of room for improvement. Therefore, this paper uses SWOT method to analyze the current situation of curriculum ideological and political construction in Heilongjiang Province in detail, in order to provide reference for improving and promoting the work.

\section{SWOT ANALYSIS OF IDEOLOGICAL AND POLITICAL CURRICULUM IN COLLEGES AND UNIVERSITIES IN HEILONGJIANG PROVINCE}

SWOT analysis is a scientific method of analyzing the situation of things based on internal and external competitive environment and conditions by determining their own strengths and weaknesses as well as external opportunities and challenges ${ }^{[1][2]}$. With the help of SWOT analysis, this paper aims to clearly understand the internal strength and weaknesses, external opportunities and threats of the curriculum ideological and political advancement in colleges and universities in Heilongjiang Province, and make a comprehensive judgment, so as to make full use of the strengths and avoid the weaknesses ${ }^{[3]}$.

\subsection{Analysis of Internal Advantages}

First, unique cultural advantages. The core of course ideological and political education is to organically integrate ideological and political education elements into each course. Heilongjiang province is famous for its northeast Resistance Spirit, Beidahuang spirit, Daqing spirit and Iron Man spirit. Colleges and universities take advantage of their unique cultural advantages to carry forward the four red spirits in accordance with local conditions, subtly enhancing students' cultural identity. At present, mudanjiang Normal University "Northeast 
Resistance spirit Selection lecture" and daqing Normal University "Iron Man Spiritual Education Practice" have achieved good teaching effects. Second, natural geographical advantages. Heilongjiang province, located in the northeast of China, is an important energy industry base and one of the largest forestry provinces in China. Colleges and universities in agriculture, forestry and characteristic industries take advantage of their unique regional advantages to actively carry out local characteristic courses to enhance students' regional identity, thus stimulating their love for the beautiful rivers and mountains of the motherland and influencing students' words and deeds silently. Third, excellent image of innovation. In November 2020, Heilongjiang province shared its experience in curriculum ideological and political construction and became the first to set an example in China. In March 2021, it will establish the first ideological and political education alliance for graduate courses in China. Among the ideological and political demonstration courses of general undergraduate education recommended by Zhejiang Province in 2021, there are 2 medical courses and 4 humanities courses, while there are 2 science and technology courses, 2 medicine courses and 2 humanities courses recommended by Heilongjiang Province. By contrast, Heilongjiang science and engineering courses have a better ideological and political integration effect.

\subsection{Internal Disadvantage Analysis}

First, the university capital investment is insufficient. In terms of education expenditure, Heilongjiang province's education expenditure accounted for $12.22 \%$ of the national education expenditure in 2019, ranking 27th in education expenditure, higher than Qinghai, Tibet, Inner Mongolia and Shanghai. In terms of educational investment, according to the implementation of educational investment in 2020, only Northeast Forestry University in Heilongjiang province ranks among the top 235 universities in China, while the educational investment of most provincial universities in coastal provinces exceeds 1 billion yuan. Second, there is a massive brain drain. By the end of 2019, Heilongjiang had 37.513 million permanent residents, 218,000 fewer than last year. According to the social development of Heilongjiang province report released in 2018, nearly five years in Heilongjiang province, outflow of population size is greater than the growth of the resources city problem is more outstanding, the Heilongjiang province local graduates employment rate is $10 \%$, out of more than $80 \%$ of the population of working age population, the greater the proportion of the higher level of cultural outflow. Among them, the outflow rate of graduate students and above is as high as $42.4 \%{ }^{[4]}$. Third, the formulation of the plan is macro. As the representative of the investigation and promotion meeting, Zhejiang Province and Heilongjiang Province have different construction work plans. In order to create a good atmosphere, Zhejiang province clearly proposes to construct a number of provincial courses, such as ideological and political demonstration courses and teaching research projects, in two batches from 2021 to 2025 , and formulate detailed construction requirements. Heilongjiang province illustrates Longjiang's characteristics from macro aspects such as guiding ideology, and lacks micro measures, which is not conducive to the in-depth promotion of ideological and political courses in colleges and universities in Heilongjiang Province.

\subsection{Analysis of External Opportunities}

First, strong support from national policies. After December 2016, the CPC Central Committee has issued 31 documents related to ideological and political work in colleges and universities in order to promote the reform of ideological and political courses. In 2016, General Secretary Xi Jinping inspected Heilongjiang Province, conducted research on forestry and put forward suggestions on innovation-driven development. In September 2018, the General Secretary put forward innovative ideas on the grain situation of Heilongjiang Agricultural Reclamation and Sanjiang River Management Bureau. From the above measures, it can be seen that the Party and the state have gradually increased their attention to the ideological and political education in Heilongjiang Province. Second, the rapid development of science and technology. The rise of science and technology in the 21 st century affects the specialty setting, discipline construction and talent training of higher education, and makes it develop towards the direction of lifelong and individualization. Based on this, curriculum ideology and politics can make full use of information technology to achieve a major breakthrough. Students acquire knowledge through multiple channels, expand learning sites and actively change learning methods with the help of science and technology and distance learning ideological and political content. Third, colleges and universities have enthusiasm for exploration and practice. Since the national College Ideological and Political Work Conference was held, colleges and universities in Heilongjiang province have carried out multi-form theoretical and practical exploration. Harbin Institute of Technology, Harbin Engineering University, Harbin University of Science and Technology and so on have issued corresponding system guarantee documents, innovative curriculum ideological and political education mode.

\subsection{Analysis of External Challenges}

First, multicultural collision. With the economic globalization, the cultural exchange and collision of various ethnic groups bring greater challenges. Heilongjiang province has profound historical accumulation. According to the statistics of the third National Cultural relics survey, there are a large number of large sites in Heilongiiang Province, which truly reflect the rich process of northeast Civilization from the Beginning of the Paleolithic Age to the present. Besides 
Heilongiiang, there are other provinces with a long history. The diversity of culture affects the formation and development of Heilongjiang region culture. At the same time, Heilongjiang province is adjacent to Russia, Japan and so on. From economy to culture to religious belief, Heilongjiang Province is integrated with foreign styles. Second, other provinces are enjoying a good momentum of development. As of May 3, 2021, the official website of the Ministry of Education released 1677 pieces of information about "ideological and political construction of curriculum", and retrieved 568 pieces of information about ideological and political construction of college curriculum. The website of the Ministry of Education nominated 4 colleges and universities in Heilongjiang Province for 11 times. Heilongjiang province, as an important speaker in the course ideological and political construction research promotion meeting, is not active enough in the course ideological and political construction promotion nationwide. The university promotion work in Heilongjiang province ranks 15th, ranking in the middle of the country. Liaoning province, also in northeast China, was nominated 19 times. Third, the motivation of classroom exploration is insufficient. According to the construction of curriculum ideology and politics published on the official website of the Ministry of Education, Shanghai, Zhejiang and other regions make full use of the resources of the third class to carry out practical activities and show students' positive feelings of home and country. For example, the youth red dream building tour, millions of teachers and students red day reading activities. Many colleges and universities in Heilongjiang province promote the construction of curriculum ideological and political construction through the practice of the second class, but in the concrete operation process, there is no large-scale curriculum ideological and political activities with Longjiang characteristics facing the whole province.

\section{SUGGESTIONS OF EDUCATION PRACTICE COURSE IN COLLEGES AND UNIVERSITIES IN HEILONGJIANG PROVINCE}

Using SWOT analysis, the formation of four different types of combination: SO combination (advantage-opportunity) settlement, ST combination (advantage-threat), WO combination (weaknesses-opportunities) and WT combination (disadvantage-threat), through different combination can be summed up the different strategies ${ }^{[5][6]}$. As shown in Figure 1.

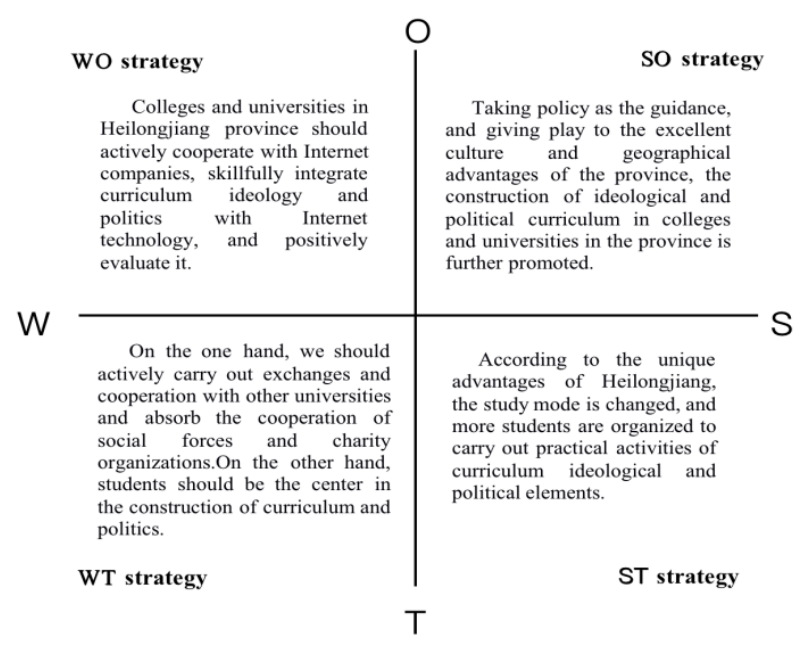

Figure 1. SWOT strategy

\subsection{Pioneering Strategy(SO)}

Heilongjiang province should continue to be policy-oriented, resolutely implement the requirements of national documents, give full play to its own resource advantages, carry out curriculum ideological and political activities according to local conditions, guide students to combine theory with practice, and deeply understand the connotation of curriculum ideological and political. Colleges and universities in the province are the main force in promoting curriculum ideological and political work. They should dare to take responsibility, constantly innovate new methods and paths suitable for the actual situation, pay attention to improve the management and incentive mechanism, and mobilize the enthusiasm of teachers and students. On the one hand, colleges and universities in Heilongjiang province should learn from the excellent experience of promoting ideological and political work in the national curriculum, and on the other hand, formulate fine work plans to provide guidance and support for the implementation of various activities.

\subsection{Confrontational Strategy(ST)}

Heilongjiang province is rich in red resources and has numerous patriotic education bases such as old revolutionary base areas and martyrs' graveyards. Heilongjiang province has changed its learning mode and improved its subjective initiative. Learn from the experience of other provinces, make use of the unique historical factors, organize practical activities related to ideological and political courses for the whole province. Through such activities, students can practice personally, stimulate students' love for the country, and make them internalize ideological and political elements in their mind and externalize them in practice. Colleges and universities in Heilongjiang province should always 
uphold the concept of integrating ideological and political elements into classroom teaching silently, use flexible teaching methods to tell Longjiang stories well, improve teaching content and update knowledge system in time.

\subsection{Strive Strategy (WO)}

Colleges and universities in Heilongjiang province clearly define their own school-running characteristics and use Internet technology to develop curriculum ideology and politics. The rapid development of science and technology promotes the development of education. First, increase cooperation with Internet technology companies. Colleges and universities should adapt to the development of The Times, through strict examination and approval mechanism, actively introduce high-quality network resources, and abandon vulgar content. Second, strengthen the integration of Internet technology and curriculum ideology and politics, skilfully integrate curriculum ideology and politics in Internet technology, based on teachers and students of colleges and universities, give full play to their own characteristics of running schools, and targeted construction of ideological and political cooperation education in colleges and universities. Third, improve the Internet technology curriculum ideological and political evaluation system. Evaluation is an important part of curriculum ideology and politics, which can supervise the work effectively. College curriculum ideological and political evaluation system should keep up with the pace of The Times, timely update the evaluation system, so as to have a clearer insight into the teaching effect.

\subsection{Defensive Strategy (WT)}

At present, the situation of education investment in Heilongjiang province is not optimistic. On the one hand, we need to expand our sources. Colleges and universities set up and cultivate a sense of competition, fully favorable policies, actively participate in the government's education investment competition, to win special financial support from the state. At the same time, we should also actively attract the support of social forces and charitable funds to relieve our financial pressure and ensure the balanced development of higher education, on the other hand, pay attention to the throttle, the course on the ideological construction, to take the student as the center, meet the demand of students at the same time, select the various cultural resources, reasonable allocation of government funding, from the teaching material, equipment, campus teachers pay the aspects such as, increased spending on education course choose economy applicable way, to reduce spending.

\section{CONCLUSION}

Through SWOT analysis, this paper makes a profound analysis of the internal status and external environment of ideological and political courses in colleges and universities in Heilongjiang Province, and believes that the combination of SO strategy and WO strategy is the best strategy. In order to make up for its own shortcomings and external threats, it is necessary to seek breakthroughs through participation consciousness, plan to make and the Internet on the basis of this strategy. In the specific practice, colleges and universities should start from their own reality, analyze the orientation and type of schools in detail, and formulate specific strategies and implementation plans in line with the schools.

\section{REFERENCES}

[1] Liu Haiyan. SWOT analysis on the implementation of curriculum ideology and politics in Jincheng vocational and technical college -- based on the investigation of current situation of curriculum ideology and politics cognition. Jincheng Journal of Vocational Technology, 2020, 13(06):4-7.

[2] Edward B. Factors in SWOT analysis applied to micro small-to-medium, and large software enterprises: an Austrian study[J]. European Management Journal, 2002, 20(5):562-573

[3] Dyson R G. Strategic development and SWOT analysis at the University of Warwick[J]. European Journal of Operational Research, 2004, 152(3):6313-640

[4] Zhao Fangliang. A brief analysis of the present situation of the investment in higher education funds in Heilongjiang. The economy and trade of the north, 2012(02):77-79.

[5] Ozcan Arslan, Osman Truan. Analytical investigation of marine casualties at the Strait of Istanbul with SWOT-AHP method[J]. Maritime Policy and Management, 2009:131-145

[6] Kalatpour O. Determing the appropriate strategies for emergency planning through AHP-SWOT[J]. Bus Contin Emer Plan, 2017(1):85-94 